\title{
MEASUREMENTS OF BED LOAD TRANSPORT ON PACIFIC Creek, Buffalo Fork AND THE SNAKe RiVER in Grand Teton NaTional Park, WYOMING
}

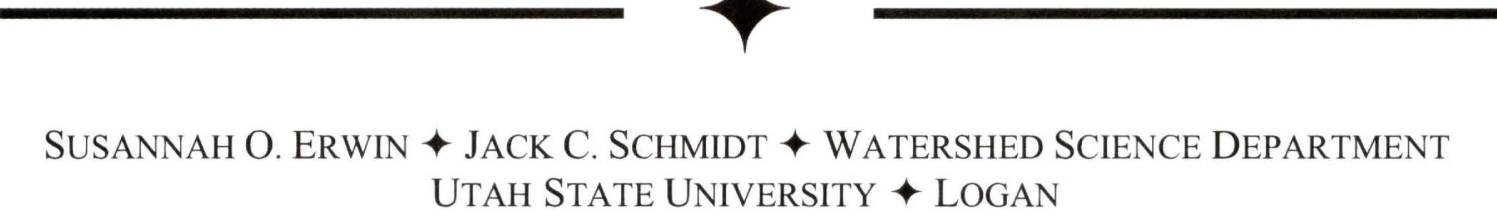

\section{$\downarrow \quad$ INTRODUCTION}

Dams disrupt the flow of both of water and sediment through a watershed. Channel morphology is a function of discharge and sediment load, and perturbations caused by dams often alter channel form, causing significant geomorphic and, potentially, ecological changes (e.g. Petts and Gurnell, 2005). At the first order, dams often produce a flow regime that is profoundly altered in the timing, magnitude, and frequency of flows (Magilligan and Nislow, 2005). Yet, the nature of channel adjustments will be specific to both the physical setting, size of the river, dam characteristics, and nature and severity of the flow regulation (Church 1995; Knighton, 1998).

Channel change analysis of the regulated Snake River in Grand Teton National Park (GTNP) has demonstrated that there have been periods of both channel narrowing and widening, but that there is no long-term progressive change (Nelson, 2007). Nevertheless, accumulation of gravel near some tributary mouths is of concern to river navigation and accumulation of gravel in braided reaches drives channel avulsions and floodplain formation. Though prior research has evaluated hydrologic changes associated with the operations of Jackson Lake Dam (JLD) (Marston et al., 2005; Nelson, 2007; Schmidt and White, 2003), little work has been done to characterize changes in the flux of sediment passing through the regulated Snake River. Thus, the processes that link dam operations with present channel characteristics are poorly understood.

In an effort to advise managers of JLD, we have developed estimates of bed load flux that can be tied to dam release schedules. These estimates are based on calibrated gravel transport relations for Pacific Creek and Buffalo Fork, the major tributaries to the Snake River downstream from the dam, and a similar relation for the Snake River at the downstream end of the study reach, the Deadmans Bar boat ramp. This report describes the data collected on Pacific Creek and Buffalo Fork in 2006 and on the Snake River at Deadmans Bar during the 2007 spring runoff season.

\section{$\downarrow \quad$ MeTHODS}

Three measurement sites were established within Grand Teton National Park for the purposes of measuring bed load transport rates. On Pacific Creek, we measured bed load transport downstream from USGS gage 13011500 (Pacific Creek at Moran WY) and approximately $650 \mathrm{~m}$ upstream from the confluence with the Snake River. On Buffalo Fork we sampled bed load transport rates downstream from USGS gage 13011900 (Buffalo Fork above Lava Creek near Moran WY) and approximately $2 \mathrm{~km}$ upstream from the 
confluence with the Snake River. On the Snake River, we measured transport approximately 500 meters downstream from the Deadmans Bar boat ramp. Discharge for the Snake River measurement site was calculated by summing the discharges measured at the gages on Pacific Creek, Buffalo Fork and the Snake River (Snake River near Moran, station number 1301100).

Bed load transport was measured at the three study sites using a Toutle River Sampler (TR-2), a type of pressure difference sampler with a 52 x $305 \mathrm{~mm}$ inlet nozzle and 1.4 expansion ratio. We modified the TR-2 by adding a front stayline to the sampler to reduce the scooping tendency associated with many large pressure-difference samplers. The stayline was attached to the mouth of the TR-2, making it possible to rapidly "jerk" the sampler off the bed prior to raising the sampler from the river bottom. A cataraft-based sampling platform was used to deploy the sampler (Fig. 1). We mounted a crane to a $4.9 \mathrm{~m}$ long cataraft and fitted the crane with an E-reel to lower the sampler to the channel bed.

The sampling boat was held stationary in the channel at predetermined intervals using roller-towers and a semi-permanent fixed cable. The system allowed us to safely repeat measurements at specified locations over a range of flows. We selected our sampling sites by considering the following factors, listed in order of importance: crew safety (i.e. the cross-section is not immediately upstream from a debris jam), simplicity of flow patterns through the crosssection, proximity to the Snake River confluence, and accessibility.

We collected samples in accordance with the Equal Width Increment method (EWI), as outlined by Edwards and Glysson (1988). Each complete measurement was comprised of one pass across the channel, consisting of 10-12 samples taken at equally spaced intervals. The duration of time the sampler remained on the bed varied between samples, from $30-240 \mathrm{sec}$, but remained constant at each interval for a given sample. The determination of the time interval used for sampling reflects a compromise between the need for a long sampling duration and the capacity of the sampling bag. Field studies suggest that measurements may become inaccurate once the sampler bag is filled beyond $40 \%$ of its capacity. Therefore, the length of time the sampler is left on the channel bottom at a single vertical must be shorter than the length of time it takes the sampler to approach its limiting capacity at the vertical where the most sediment is moving. We regularly reassessed the sampling time interval as flow and sediment transport conditions changed.

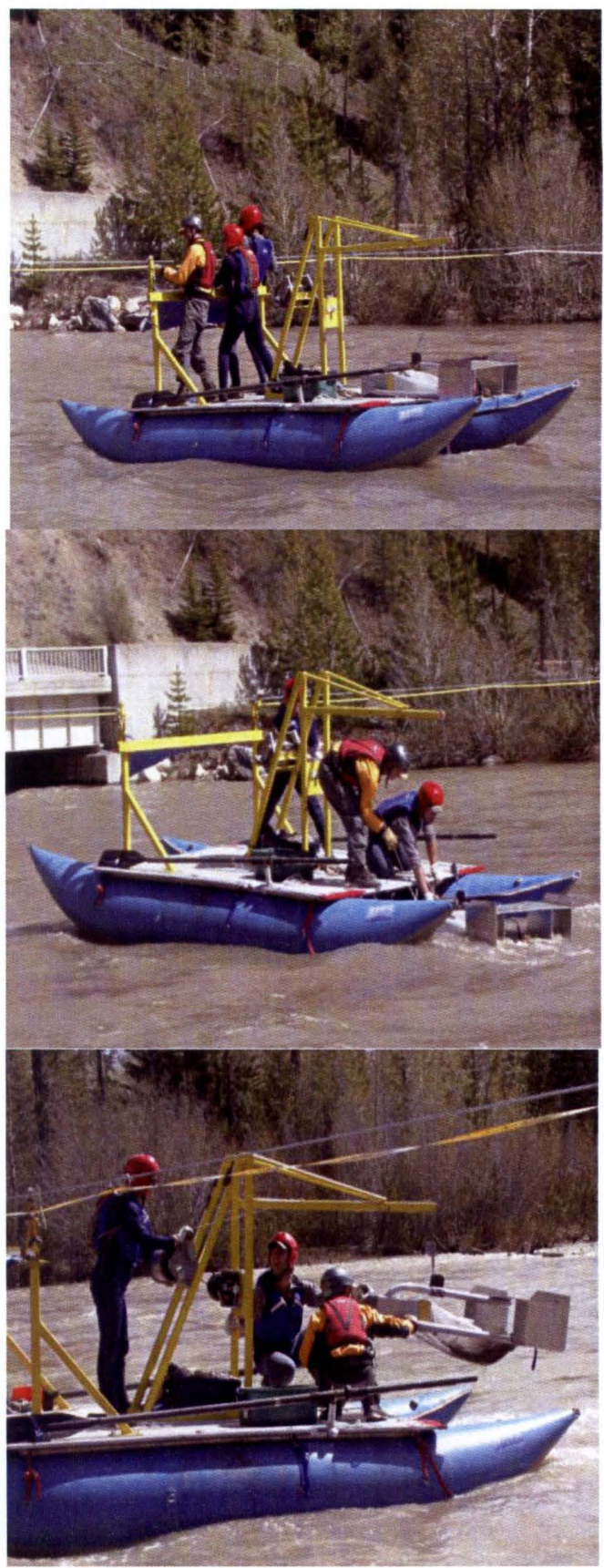

Figure 1. Sampling bed load transport rates on Pacific Creek: (A) moving the boat across the cable using the roller-towers; (B) deploying the sampler; and (C) retrieving the sampler from the bed with a partially filled bag of sediment. 
Bed load samples were processed in the Fluvial Geomorphology Lab at USU. Coarse organic material was removed by hand from each sample prior to sieving. We then sieved the portion of each sample that was greater than 2 $\mathrm{mm}$ into $2^{0.5}$ fractions to determine the grain size distribution of the bed load. First, we used a hand-held rocker sieve to separate those size fractions greater than $11.3 \mathrm{~mm}$. The remainder of each sample was then split using a splitter. We processed the split fraction using a shaker sieve. All sediment less than $2 \mathrm{~mm}$ was weighed. Because these particles are transported in suspension as well as bed load, they were disregarded when constructing calibrated bed load transport models.

\section{$\downarrow \quad$ RESUltS}

We sampled bed load transport rates during the 2006 spring runoff season on Pacific Creek and Buffalo Fork and during 2007 spring runoff season on Snake River at Deadmans Bar .
Samples were collected over a range of discharges at each sampling site: $26-144 \mathrm{~m}^{3} / \mathrm{s}$ on Pacific Creek (35 - 200\% of the 2-yr flood), $45-117 \mathrm{~m}^{3} / \mathrm{s}$ on Buffalo Fork $(35-105 \%$ of the 2-yr flood), and $48-181 \mathrm{~m}^{3} / \mathrm{s}$ on Snake River (20-60\% of the $2-y r$ flood). In total, 24 samples were collected on Pacific Creek, 39 on Buffalo Fork and 62 on Snake River. Sample from the three sites ranged in size from a few hundred grams to as much as $136 \mathrm{~kg}$ on Pacific Creek during peak flows.

Patterns in bed load transport rates differed among the three measurement sites (Fig. 2). On Pacific Creek and Snake River at Deadmans Bar, bed load transport tracked well with changes in discharge. On Snake River, measurements of bed load transport rates ranged from $<1$ to $200 \mathrm{gm}^{-1} \mathrm{~s}^{-1}$. Although we were able to collect samples during flows of at least the magnitude of the 2-yr flood on both tributaries, this was not the case at Deadmans Bar, where the width of the channel and water velocities limited our ability to collect samples at higher flows.

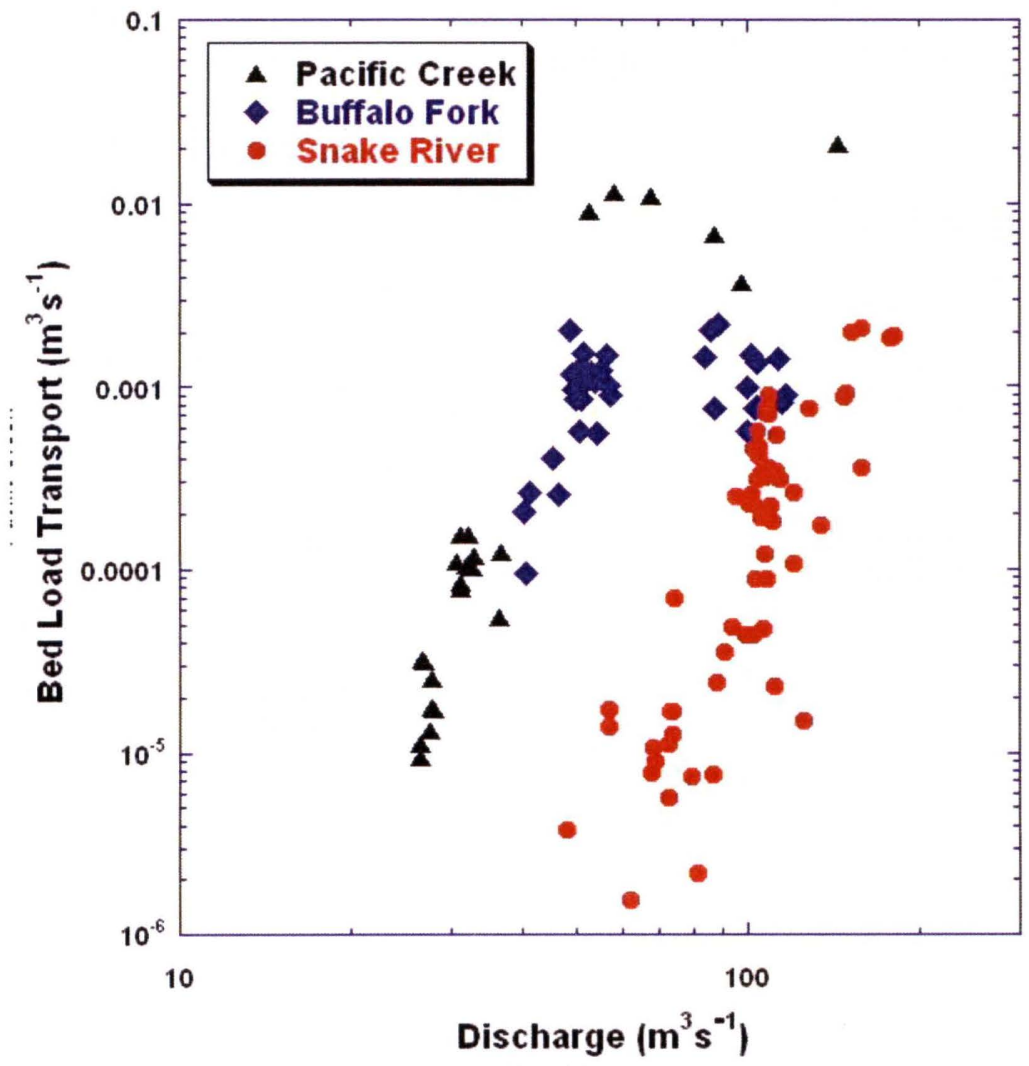

Figure 2. Bed load transport data collected on during 2006 on Pacific Creek and Buffalo Fork, and during 2007 on the Snake River. 
On Pacific Creek, we measured much higher bed load transport rates than at either of the other two sampling sites, with measured rates ranging from 1 to $1300 \mathrm{gm}^{-1} \mathrm{~s}^{-1}$. These high transport rates reflect a unique spring runoff event that marked our sampling season: the peak flow of record on Pacific Creek, $164 \mathrm{~m}^{3} \mathrm{~s}^{-1}$, occurred on May 23, 2006. While we did not sample transport rates during the instantaneous peak, we did collect measurements on the day of the peak just prior to and after the time at which record flows were recorded at the gaging station. The measurements made in the vicinity of the peak discharge showed the most scatter of the samples collected at the Pacific Creek measurement site. It was during this period of high flows that sampling time were shortest (30 sec per vertical), because the capacity of our sampler bag was quickly exceeded.

On Buffalo Fork, measured bed load transport rates ranged from 25 to $180 \mathrm{gm}^{-1} \mathrm{~s}^{-1}$. The Buffalo Fork bed load transport measurements displayed substantially more scatter than the data collected at either of the two field sites. The range of bed load transport rates measured from June 7 to June 9 was comparable to the range of transport rates measured from June 17 to June 21, despite the fact that magnitude of discharge was half as great during the later period of time (Fig. 2). This trend in the data appears to demonstrate counter-clockwise hysteresis, where transport rates were larger on the falling limb than on the rising limb. Although this finding runs contrary to typical patterns, there is some precedence for counter-clockwise hysteresis in natural rivers (Reid et al., 1985). However, it is difficult to discern the exact nature of the pattern on Buffalo Fork because our measurements of bed load transport were discontinuous.

\section{$+\quad$ SUMMARY}

Bed load transport rates were measured on both Pacific Creek and Buffalo Fork over a range of discharges 2006 and on the Snake River in 2007. These data are being used to calibrate transport relations, and ultimately to estimate the influx and efflux of sediment through the Snake River, from Jackson Lake Dam to Deadman's Bar. This data will allow us to predict and better understand the impacts of alternative dam release schedules on the Snake River in Grand Teton National Park.

\section{$\downarrow$ ACKNOWLEDGEMENTS}

This project received funding from the U.S. Geologic Survey Northern Rocky Mountian Science Center, Grand Teton National Park and the University of Wyoming-National Park Service Research Center. Housing was provided by the University of Wyoming-National Park Service Research Center during 2006. The Teton Science School provided housing during 2007 field work.

\section{$\downarrow$ Literature Cited}

Church, M.A. 1995. Geomorphic response to river flow regulation: case studies and time-scales. Regulated Rivers: Research and Management 11(1), 3-22.

Edwards, T.K., G.D. Glysson. 1988. Field Methods for Measurement of Fluvial Sediment.U.S. Geological Survey Techniques of Water-Resources Investigations, Book 3, Chapter C2.

Knighton, D., 1998. Fluvial forms and processes: A new perspective. Hodder Arnold Publications.

Magilligan, F.J., K.H. Nislow. 2005. Changes in hydrologic regime by dams. Geomorphology 71; 61-78.

Marston, R.A., J.D. Mills, D.R. Wrazien, B. Basset, D.K. Splinter. 2005. Effects ofJackson Lake Dam on the Snake River and its floodplain, Grand Teton National Park, Wyoming, USA. Geomorphology 71, 79-98.

Nelson, N.C. 2007. Hydrology and Geomorphology of the Snake River in Grand Teton National Park, Wyoming. M.S. Thesis, Utah State University.

Petts, G.E. and A.M. Gurnell. 2005. Dams and geomorphology: Research progress and future directions. Geomorphology 71, $27-47$. 
Reid, I., L.E. Frostick, J.T. Layman. 1985. The incidence and nature of bedload transport during flood flows in coarsegrained alluvial channels. Earth Surface Processes and Landforms.

Schmidt, J.C., M.A. White. 2003. The hydrologic regime of the Snake River in Grand Teton National Park and associated channel change, Draft Report. Cooperative Agreement CA1200-99-007. Utah State University. 